\title{
Premalignant Changes in the Bronchial Epithelium Are Prognostic Factors of Distant Metastasis in Non-Small Cell Lung Cancer Patients
}

\author{
Olga V. Pankova ${ }^{1 *}$, Liubov A. Tashireva ${ }^{1}$, Evgeny O. Rodionov ${ }^{1}$, Sergey V. Miller ${ }^{1}$, \\ Sergey A. Tuzikov ${ }^{1}$, Dmitry S. Pismenny ${ }^{1}$, Tatiana S. Gerashchenko ${ }^{1}$, \\ Marina V. Zavyalova ${ }^{1,2}$, Sergey V. Vtorushin ${ }^{1,2}$, Evgeny V. Denisov ${ }^{1,3}$ \\ and Vladimir M. Perelmuter ${ }^{1}$ \\ ${ }^{1}$ Cancer Research Institute, Tomsk National Research Medical Center, Tomsk, Russia, ${ }^{2}$ Department of Pathological Anatomy, \\ Siberian State Medical University State Medical University, Tomsk, Russia, ${ }^{3}$ Department of Organic Chemistry, Tomsk State \\ University, Tomsk, Russia
}

OPEN ACCESS

Edited by: Jun Zhang,

University of Kansas Medical Center, United States

Reviewed by:

Vijaya Iragavarapu-Charyulu, Florida Atlantic University, United States

Qi Zhang,

Houston Methodist Research Institute, United States

*Correspondence: Olga V. Pankova pancova@oncology.tomsk.ru

Specialty section: This article was submitted to Thoracic Oncology, a section of the journal

Frontiers in Oncology

Received: 07 September 2021 Accepted: 20 October 2021 Published: 10 November 2021

Citation:

Pankova OV, Tashireva LA Rodionov EO, Miller SV, Tuzikov SA, Pismenny DS, Gerashchenko TS,

Zavyalova MV, Vtorushin SV, Denisov EV and Perelmuter VM (2021) Premalignant Changes in the Bronchial Epithelium Are Prognostic Factors of Distant Metastasis in Non-Small Cell Lung Cancer Patients.

Front. Oncol. 11:771802. doi: 10.3389/fonc.2021.771802
Background: The study assessed the possibility of dividing patients into groups based on the assessment of morphological changes in the epithelium of small-caliber bronchi located near the primary tumor in order to predict high and low risks of distant metastasis of non-small cell lung cancer.

Methods: In 171 patients with non-small cell lung cancer $\left(\mathrm{T}_{1-4} \mathrm{~N}_{0-3} \mathrm{M}_{0}\right)$ in small-caliber bronchi taken at a distance of 3-5 cm from the tumor, various variants of morphological changes in the bronchial epithelium (basal cell hyperplasia $(\mathrm{BCH})$, squamous cell metaplasia (SM), and dysplasia (D)) were assessed. Long-term results of treatment, namely, distant metastasis, were assessed after 2 and 5 years.

Results: During the follow-up period, distant metastases were found in 35.1\% (60/171) of patients. Most often, they were observed in patients of the high-risk group: $\mathrm{BCH}+\mathrm{SM}-\mathrm{D}-$ (51.6\%, 40/95) and $\mathrm{BCH}-\mathrm{SM}+\mathrm{D}+(54.4 \%, 6 / 11)$. Less often, distant metastases were observed in low-risk group patients: $\mathrm{BCH}+\mathrm{SM}+\mathrm{D}-(6.7 \%, 3 / 45)$ and $\mathrm{BCH}-\mathrm{SM}-\mathrm{D}-$ (10.0\%, 2/20). Tumor size, grade, and stage were significant predictors of metastasis only in the high-risk group. The 5-year metastasis-free survival was better in the low-risk group of distant metastases.

Conclusions: Isolated $\mathrm{BCH}$ or dysplasia in small bronchi distant from foci of tumor is associated with a high-risk distant metastasis and less 5-year metastasis-free survival.

Keywords: non-small cell lung cancer (NSCLC), bronchial lesion, distant metastasis, metastasis-free survival, basal cell hyperplasia, squamous cell metaplasia

\section{INTRODUCTION}

The most common cause of cancer death in 2020 was lung cancer (1). High mortality is associated with the progression of the tumor process. Therefore, the search for various molecular biological markers involved in the mechanisms of distant metastasis in non-small cell lung cancer (NSCLC) remains relevant. The identification of patients with a high risk of tumor progression can be used to 
adequately prescribe adjuvant chemotherapy (AC) and to adjust its regimen in order to minimize adverse effects.

The most important factors associated with progression of NSCLC and predicting survival are tumor stage, histologic structure, grade, and biological aggressiveness (2-5). However, these factors are not always effective in predicting the outcome of the tumor process. Our earlier study showed that different variants of the combination of morphological changes in the epithelium of small bronchi [basal cell hyperplasia $(\mathrm{BCH})$, squamous cell metaplasia (SM), and dysplasia (D)], distant from foci of squamous cell carcinoma and lung adenocarcinoma, are associated with recurrence. The combination of $\mathrm{BCH}$ and $\mathrm{SM}$ is associated with high risk of recurrence of NSCLC regardless of the histologic type of tumor and neoadjuvant chemotherapy (NAC) $(6,7)$. In this study, we considered the association of different variants of morphological changes of the respiratory epithelium of small bronchi adjacent to the tumor as risk factors for distant metastasis.

\section{METHODS}

\section{Patients}

The study enrolled 171 patients with NSCLC (squamous cell carcinoma and adenocarcinoma, $\mathrm{T}_{1-4} \mathrm{~N}_{0-3} \mathrm{M}_{0}$ ) who were treated in the Cancer Research Institute, Tomsk NRMC, between 2005 and 2011. Patients were excluded if they were refused surgery and had an Eastern Cooperative Oncology Group (ECOG)/WHO performance score $>2$, small-cell lung cancer, associated severe diseases, and cardiovascular and pulmonary decompensation. Metastatic involvement was identified from the Local Cancer Register. The study was approved by the Institutional Review Board (IRB) (December 10, 2012; the number of approvals is 16).

The histologic diagnosis of lung cancer was made according to the International Association for the Study of Lung Cancer/ American Thoracic Society/European Respiratory Society (IASLC/ATS/ERS) lung adenocarcinoma classification (8) and the WHO criteria (9) and was confirmed by immunohistochemistry using a panel of antibodies: TTF-1 (clone 8G7G3/1, Dako), Napsin A (Rabbit Polyclonal, Cell Marque), and p63 (Rabbit Polyclonal, Leica) (Figure 1).

Cancer stage was determined according to the TNM classification (10). The type of morphological lesions in the bronchial epithelium (BCH, SM, and D) of small bronchi $(\mathrm{d}=$ $0.5-2 \mathrm{~mm}$ ), obtained at a distance of $\sim 3 \mathrm{~cm}$ from the tumor edge during surgery, was assessed as described earlier (11).

\section{Statistical Analysis}

The data were analyzed with the statistical software STATISTICA 12 (StatSoft, OK, USA) and GraphPad Prism 9 (GraphPad Software, San Diego, CA, USA). A multivariate logistic regression model was used to calculate odds ratios (OR) for type of bronchial lesions, histologic type, recurrence, type of therapy, gender, smoking status, grade, and stages T and $\mathrm{N}$.
p-Values for $2 \times 2$ tables were obtained by using Fisher's exact test. Survival was investigated with univariate and multivariate Cox regression models, yielding hazard ratios (HRs). This model adjusted for type of bronchial lesions, histologic type, recurrence, type of therapy, gender, smoking status, grade, and stages $\mathrm{T}$ and N. Metastasis-free survival (MFS) was calculated by the KaplanMeier method, and differences in survival curves among the groups were evaluated by the $\log$ rank test. $\mathrm{p}<0.05$ was considered statistically significant.

\section{RESULTS}

Over the entire follow-up period, distant metastases occurred in $35.1 \%(60 / 171)$ of patients with NSCLC. The clinical and pathological parameters of NSCLC patients depending on the presence or absence of distant metastasis are presented in Table 1.

Of those cases that developed metastasis, $81.7 \%(49 / 60)$ had $\mathrm{BCH}+\mathrm{SM}-\mathrm{D}-; 10.0 \%(6 / 60), \mathrm{BCH}-\mathrm{SM}+\mathrm{D}+; 5.0 \%(3 / 60)$, $\mathrm{BCH}+\mathrm{SM}+\mathrm{D}-$; and $3.3 \%(2 / 60), \mathrm{BCH}-\mathrm{SM}-\mathrm{D}-$. Patients with $\mathrm{BCH}+\mathrm{SM}-\mathrm{D}-$ and $\mathrm{BCH}-\mathrm{SM}+\mathrm{D}+$ had the highest percentage (51.6\% (49/95) and 54.5\% (6/11), respectively) of metastasis than had $\mathrm{BCH}+\mathrm{SM}+\mathrm{D}-[6.7 \%(3 / 45)]$ and $\mathrm{BCH}-\mathrm{SM}-\mathrm{D}-[10.0 \%$ $(2 / 20)]$ patients.

Based on these results, we identified two groups of patients: with low $(\mathrm{BCH}-\mathrm{SM}-\mathrm{D}-$ and $\mathrm{BCH}+\mathrm{SM}+\mathrm{D}-)$ and high $(\mathrm{BCH}+$ $\mathrm{SM}-\mathrm{D}-$ and $\mathrm{BCH}-\mathrm{SM}+\mathrm{D}+$ ) risk of distant metastases. We used univariate and multivariate prognostic analyses to assess the prognostic effect of the risk score system based on type of bronchial lesions and clinical and pathologic parameters of NSCLC patients (Table 2).

In the univariate logistic regression analysis, the high-risk group $(\mathrm{OR}=12.9 ; 95 \% \mathrm{CI}=4.8-34.7, \mathrm{p}<0.001)$, $\mathrm{T} 3-4(\mathrm{OR}=3.4$; $95 \% \mathrm{CI}=1.5-7.7, \mathrm{p}=0.002)$, grade $3(\mathrm{OR}=3.6$; $95 \% \mathrm{CI}=1.6-$ $7.9, \mathrm{p}=0.001)$, and stage III $(\mathrm{OR}=5.1 ; 95 \% \mathrm{CI}=2.2-11.8, \mathrm{p}=$ 0.0001 ) were significantly associated with higher risks of distant metastasis. The ORs of histologic type, nodal status, recurrence, NAC, intraoperative radiotherapy (IORT), gender, smoking status, and AC ( $\mathrm{p}>0.05)$ were insignificant in the univariate logistic regression analysis. The multivariate logistic regression models (all variables and variables significant after univariate analysis) confirmed that the high-risk group, T3-4, grade 3, and stage III (OR $>1 ; p<0.001)$ were still significantly associated with higher risks of metastasis. As a result, based on OR, being a high-risk group was the most influential risk factor for distant metastasis of NSCLC.

The frequency of the stage $\mathrm{T}$ at diagnosis and the grade between the low- and high-risk groups were not significant (Fisher's exact test, $\mathrm{p}>0.05$ ) (Figure 2).

This, as well as no correlation between stage $\mathrm{T}$ and grade $\left(\mathrm{r}^{2}=\right.$ $0.3448, \mathrm{p}=0.6998)$, may indicate the independence of three factors in the distant metastasis prognosis. The results presented in Table 3 allow us to compare the significance of three factors (risk groups, T, and grade) to determine the rate of developing distant metastases in NSCLC. 

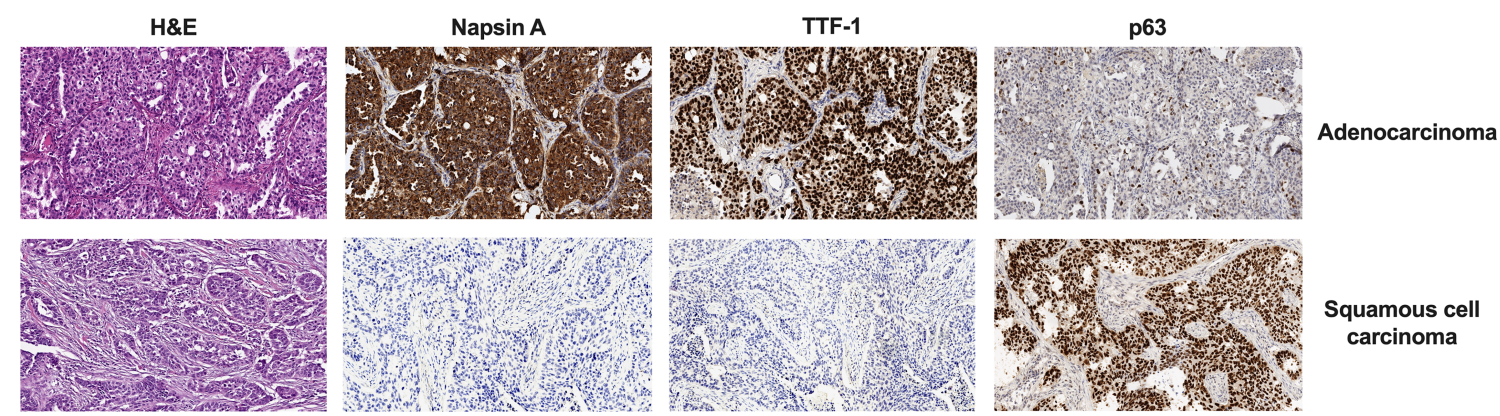

Squamous cell carcinoma

FIGURE 1 | Difference in H\&E and IHC staining of two histologic types of NSCLC. Magnification, $\times 100$. IHC, immunohistochemistry; NSCLC, non-small cell lung cancer.

There is every reason to believe that the assignment of patients to high- and low-risk groups by the risk score system based on type of bronchial lesions is the most significant and independent prognostic factor of distant metastasis. Moreover, it is acceptable to believe that T3-4 and grade 3 are unfavorable factors only in the high-risk group of distant metastases.

We described the frequency of metastases depending on the cancer stage and the grade, separately for the low- and high-risk groups (Figure 3).

The evaluation of the relationship of distant metastasis of NSCLC with the cancer stage showed that in BCH-SM-Dgroup single distant metastases occurred only in patients with stage IIIA, 16.7\% (2/12) (Figure 3A). In another low-risk group $(\mathrm{BCH}+\mathrm{SM}+\mathrm{D}-)$, metastases were in $11.1 \%(1 / 9)$ of patients with stage IIB, in $8.3 \%(1 / 12)$ of patients with IIIA, and in $9.09 \%$ (1/ 11) of patients with stage IIIB (Figure 3B).

There were no metastases in the low-risk group of distant metastases in I-II stage during the observation period, while in the high-risk group of distant metastases $(\mathrm{BCH}+\mathrm{SM}-\mathrm{D}-$ and $\mathrm{BCH}-\mathrm{SM}+\mathrm{D}+)$, metastases occurred at any cancer stage (Figures 3C, D). From Table 4, it follows that only the highrisk group of distant metastases is associated with the cancer stage $(\mathrm{p}=0.0028)$.

The comparison of the rates of metastasis in cases with stage IIIA shows that at the same stage, the frequency of metastasis in the high-risk group is 20 times higher than in the low-risk group.

\section{Survival Analyses}

We explored the potential prognostic factors in NSCLC patients using univariate and multivariate Cox regression analyses. None of the investigated parameters in univariate and multivariate Cox analyses influenced 2-year MFS in NSCLC patients (Table 5).

As shown in Table 6, the univariate Cox regression analysis revealed that the $\mathrm{BCH}+\mathrm{SM}-\mathrm{D}-$ type of bronchial lesions was significantly associated with poor 5-year MFS in patients with NSCLC.

The multivariate Cox regression analysis showed that the $\mathrm{BCH}+\mathrm{SM}-\mathrm{D}-$ type of bronchial lesions was an independent prognostic factor for the 5-year MFS. The Kaplan-Meier plots indicated that NSCLC patients with $\mathrm{BCH}+\mathrm{SM}-\mathrm{D}-$ exerted significantly worse survival than the patients with other type of bronchial lesions ( $p<0.05$; Figure 4).

The survival rates of NSCLC patients with different types of bronchial lesions who were alive for 5 years was $52.0 \%$ at $\mathrm{BCH}$ $+\mathrm{SM}-\mathrm{D}-, 97.5 \%$ at $\mathrm{BCH}+\mathrm{SM}+\mathrm{D}-, 80.0 \%$ at $\mathrm{BCH}-\mathrm{SM}+\mathrm{D}+$, and $100.0 \%$ at $\mathrm{BCH}-\mathrm{SM}-\mathrm{D}-$.

Even more clearly, the association between the type of bronchial lesions and the frequency of distant metastasis was demonstrated when evaluating the curves of 5-year MFS in the low- and high-risk groups (Figure 5).

The survival rates of the high-risk and low-risk groups of patients who were either diagnosed with NSCLC or who were alive at 5 years were $52.5 \%$ and $98.2 \%$, respectively.

\section{DISCUSSION}

The results of the study indicate that the state of the epithelium in the small bronchi distant from the tumor can be considered as a factor that can be used to divide patients with NSCLC into groups of low and high risk of distant metastasis. The absence of changes in the epithelium (BCH-SM-D-) or the combination of $\mathrm{BCH}$ with squamous metaplasia $(\mathrm{BCH}+\mathrm{SM}+\mathrm{D}-)$ is associated with a low frequency of metastasis ( $10 \%$ or $6.7 \%$, respectively). A high risk of distant metastases is associated with the isolated $\mathrm{BCH}(\mathrm{BCH}+\mathrm{SM}-\mathrm{D}-)$ and $\mathrm{SM}$ combined with $\mathrm{D}$ of the respiratory epithelium $(\mathrm{BCH}-\mathrm{SM}+\mathrm{D}+)$.

Metastases in these groups were found in $51.6 \%$ and $54.5 \%$ of cases. The significance of the type of morphological premalignant changes in the epithelium of small bronchi is a predictor of the incidence of distant metastases, and the time of their clinical manifestation is also confirmed by the results of the Cox regression analyses. In the low-risk group of distant metastases, 5-year MFS was higher. It is noteworthy that the study demonstrated the significance of generally recognized factors in predicting distant metastasis: tumor size, grade, and stage of the process. However, an important innovation lies in the fact that these factors have a significant prognostic ability precisely in the high-risk group, stratified by type of bronchial lesions. 
TABLE 1 | Clinicopathologic features of NSCLC patients with or without distant metastases.

\begin{tabular}{|c|c|c|c|}
\hline Parameter & \multicolumn{2}{|c|}{ Number of patients, $\mathrm{n}(\%)$} & p \\
\hline \multicolumn{4}{|l|}{ Gender } \\
\hline $\mathrm{F}$ & $5 / 60(8.3)$ & 23/111 (20.7) & 0.05 \\
\hline Age & $57.1 \pm 4.2$ & $58.3 \pm 8.6$ & \multirow[t]{2}{*}{0.51} \\
\hline Smoking & $49 / 60(81.7)$ & 79/111 (71.2) & \\
\hline Squamous cell carcinoma & $41 / 60(68.3)$ & 66/111 (59.5) & \multirow[t]{2}{*}{0.32} \\
\hline Adenocarcinoma & $19 / 60(31.7)$ & $45 / 111(40.5)$ & \\
\hline \multicolumn{4}{|l|}{ Stage } \\
\hline । & 2/60 (3.3) & 12/111 (10.8) & 0.07 \\
\hline$\| \mathrm{A}$ & 2/60 (3.3) & 7/111 (6.3) & 0.38 \\
\hline IIB & $5 / 60(8.3)$ & 29/111 (26.1) & 0.005 \\
\hline $\mathrm{T}_{3-4}$ & $51 / 60(85.0)$ & $69 / 111(62.2)$ & 0.002 \\
\hline \multicolumn{4}{|l|}{ Grade } \\
\hline 1 & 2/60 (3.3) & $8 / 111(7.2)$ & 0.27 \\
\hline 2 & $48 / 60(80.0)$ & $56 / 111(50.5)$ & 0.0003 \\
\hline 3 & $10 / 60(16.7)$ & $47 / 111(42.3)$ & 0.0011 \\
\hline \multicolumn{4}{|l|}{ Nodal status } \\
\hline Positive & $31 / 60(51.7)$ & $51 / 111(45.9)$ & \multirow[t]{2}{*}{0.45} \\
\hline Negative & 29/60 (48.3) & $60 / 111(54.1)$ & \\
\hline \multicolumn{4}{|l|}{ Recurrence } \\
\hline Yes & $3 / 60(5.0)$ & 20/111 (18.0) & 0.48 \\
\hline No & $57 / 60(95.0)$ & $91 / 111(82.0)$ & 0.02 \\
\hline \multicolumn{4}{|l|}{ NAC } \\
\hline \multicolumn{4}{|l|}{$\mathrm{AC}$} \\
\hline Yes & $31 / 60(51.7)$ & $50 / 111(45.05)$ & \multirow[t]{2}{*}{0.426} \\
\hline No & $29 / 60(48.3)$ & $61 / 111(54.95)$ & \\
\hline $\mathrm{AC}$ regimen & & & \\
\hline Vinorelbine/carboplatin & 9/60 (15.0) & $21 / 111$ (18.9) & 0.51 \\
\hline Paclitaxel/carboplatin & $12 / 60(20.0)$ & $14 / 111$ (12.6) & 0.23 \\
\hline Gemcitabine/carboplatin & 6/60 (10.0) & $13 / 111(11.7)$ & 0.69 \\
\hline Irinotecan/carboplatin & $2 / 60(3.3)$ & 2/111 (1.8) & 0.61 \\
\hline Etoposide/cisplatin & 2/60 (3.3) & $0 / 111(0.0)$ & 0.07 \\
\hline
\end{tabular}

Fisher's exact test was used.

MTS, distant metastasis; NSCLC, non-small cell lung cancer; NAC, neoadjuvant chemotherapy; IORT, intraoperative radiotherapy; AC, adjuvant chemotherapy.

It is known that microenvironment determines the invasiveness and ability of cells to intravasate, which is the first step in the metastatic process. This view explains the probability of a complex chain of cause-and-effect relationships between parenchymal-stromal relationships in small bronchi located near the tumor and the risk of distant metastasis of NSCLC.

The results of the study suggest that the variant of a combination of different types of morphological and molecular changes in the bronchial epithelium under conditions of chronic inflammation in the bronchi (in chronic bronchitis or NSCLC) is a stable condition reflecting the constitutive features of stromalparenchymal relationships during inflammation and the divergent nature of the progression of precancerous changes in the bronchial epithelium.

Previously, we analyzed the expression profiles of the $\mathrm{BCH}$, $\mathrm{SM}$, and $\mathrm{D}$ genes in small bronchi near the primary tumor in NSCLC. It was found that isolated $\mathrm{BCH}$ in the high-risk group of distant metastasis differs from the $\mathrm{BCH}$ combined with SM in the 
TABLE 2 | Univariate and multivariate logistic regression analyses of factors associated with distant metastasis in NSCLC patients.

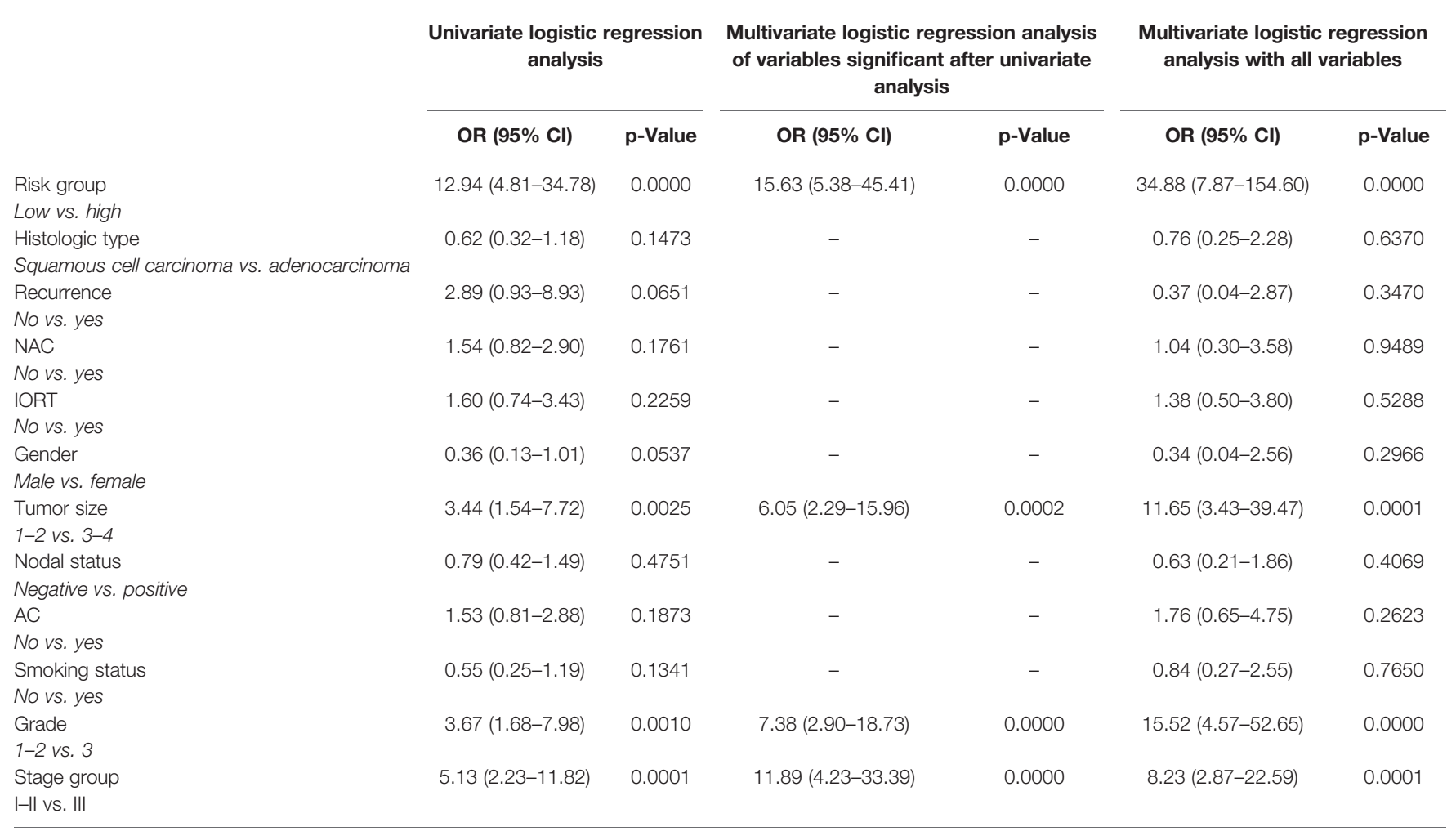

NSCLC, non-small cell lung cancer; NAC, neoadjuvant chemotherapy; IORT, intraoperative radiotherapy; AC, adjuvant chemotherapy.

low-risk group of metastases $(\mathrm{BCH}+\mathrm{SM}+\mathrm{D}-)$ by the expression of immune response genes. Increased expression of genes for regulation of the cell cycle and downregulation of genes for assembly of cilia of the epithelium distinguish SM combined with $\mathrm{D}$ in the second high-risk group $(\mathrm{BCH}-\mathrm{SM}+\mathrm{D}+)$ from $\mathrm{SM}$, which is combined with $\mathrm{BCH}$ in the group of low risk of metastasis $(\mathrm{BCH}+\mathrm{SM}+\mathrm{D}-)$. Finally, in the epithelium with dysplastic changes, overexpression of genes regulating cell division and insufficient expression of genes regulating inflammation are noted (7). The described differences in gene expression suggest variability in epithelial-stromal relationships, including the nature of inflammation and the response of the epithelium to inflammation-associated cytokines, with different combinations of morphological changes in the respiratory epithelium. Because of this, it can be expected that different variants of epithelial-stromal relations in small bronchi adjacent
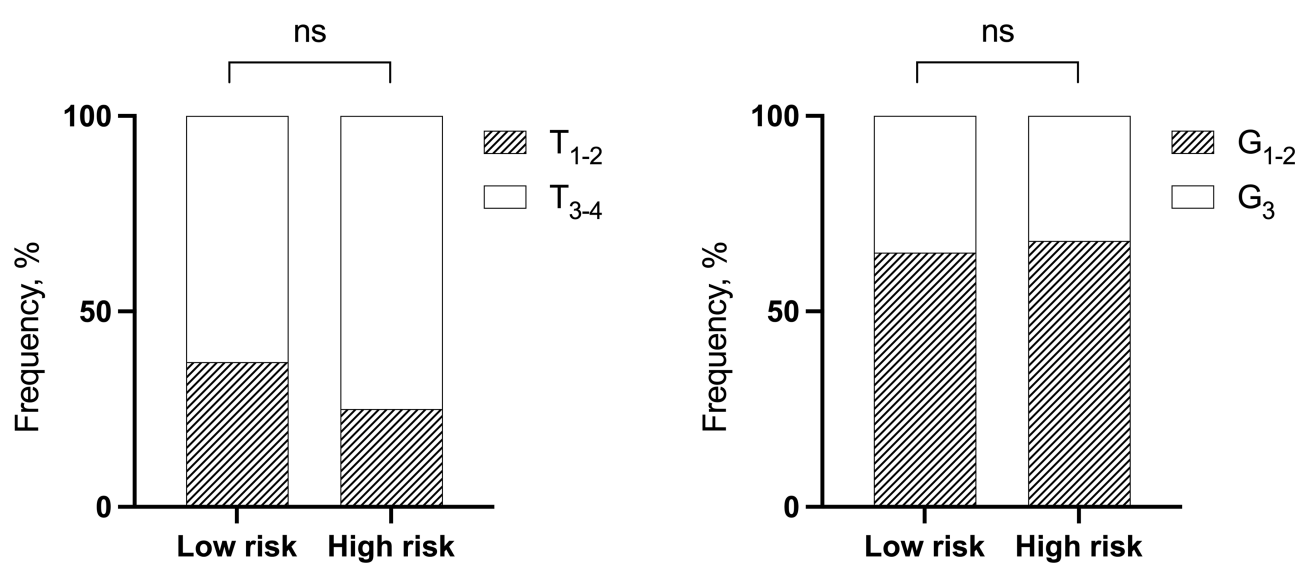

FIGURE 2 | The distribution of NSCLC patients by T and grade depending on low- and high-risk groups of distant metastases. Fisher's exact test. NSCLC, nonsmall cell lung cancer; ns, not significant. 
TABLE 3 | The frequency of distant metastases depending on the cancer stage and the grade, separately for the low- and high-risk in NSCLC patients.

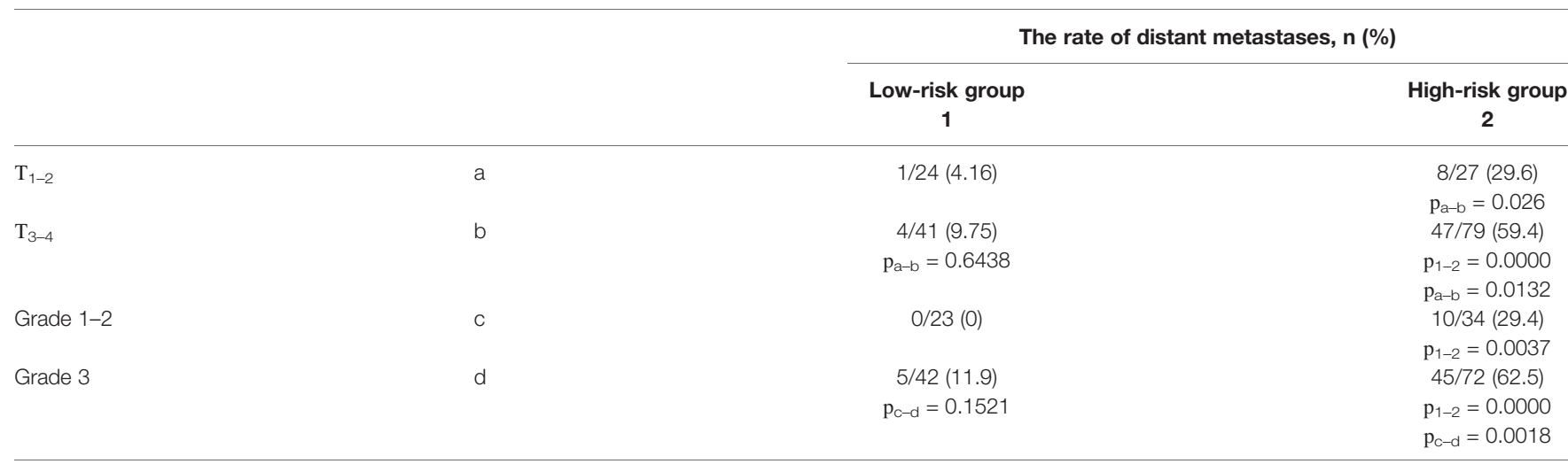

Fisher's exact test was used.

to the tumor, which may have a constitutive nature, may be associated with different variants of parenchymal-stromal relations in carcinomas, which substantially determine the risk of distant metastasis.
Unfortunately, prior to this study, there was no concept of morphological changes in the epithelium of small bronchi as a factor associated with distant metastasis, and their prognostic significance in patients with NSCLC. Numerous studies are aimed

\section{Low risk group}

A

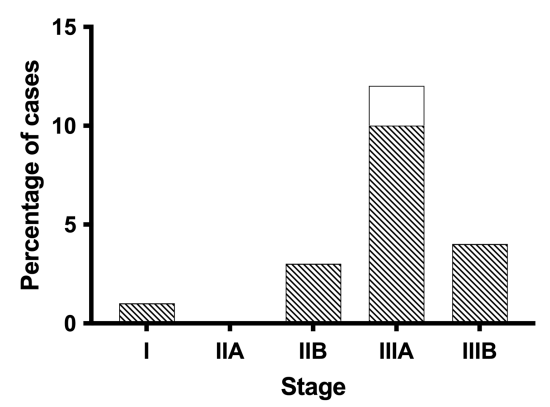

B

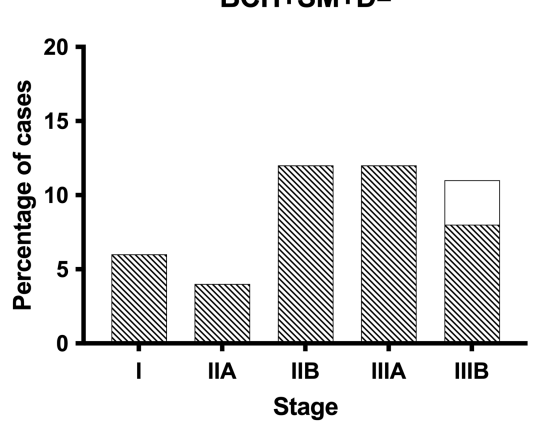

High risk group

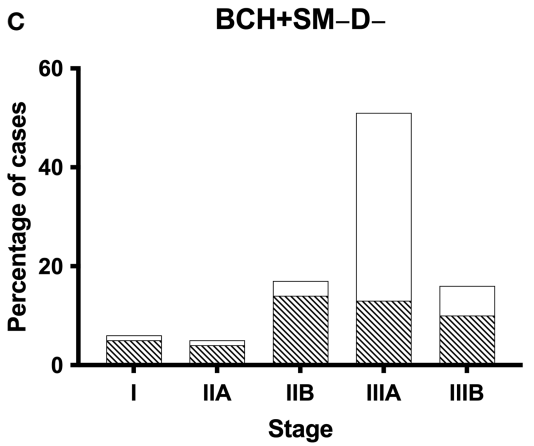

$\mathbb{N}$ Mts no
D

$\mathrm{BCH}-\mathrm{SM}+\mathrm{D}+$

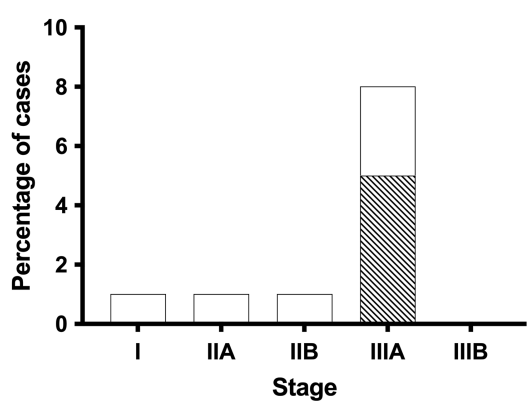

Mts yes

FIGURE 3 | The frequency of distant metastases in NSCLC patients with different bronchial lesions (A-D) depending on the cancer stage. BCH, basal cell hyperplasia; SM, squamous metaplasia; D, dysplasia; Mts, distant metastases; NSCLC, non-small cell lung cancer. 
TABLE 4 | The frequency of distant metastases in groups of high and low risk of metastasis, depending on the cancer in NSCLC patients.

\begin{tabular}{|c|c|c|c|}
\hline Stage & & \multicolumn{2}{|c|}{ The frequency of distant metastases, $n(\%)$} \\
\hline । & a & $0 / 7(0)$ & $\begin{array}{l}2 / 7(28.57) \\
p=0.4615\end{array}$ \\
\hline$\| \mathrm{A}$ & $b$ & $0 / 4(0)$ & $\begin{array}{l}2 / 6(33.33) \\
p=0.4667\end{array}$ \\
\hline IIB & c & 0/15 (0) & $\begin{array}{l}4 / 18(22.22) \\
p=0.1081\end{array}$ \\
\hline IIIB & e & $3 / 15(20.00)$ & $\begin{array}{l}6 / 16(37.50) \\
p=0.4331\end{array}$ \\
\hline$p$-Value & & $\mathrm{p}_{\mathrm{abc}-\mathrm{de}}=0.0777$ & $p_{a b c-d e}=0.0028$ \\
\hline
\end{tabular}

Fisher's exact test was used.

at characterizing different types of changes in the epithelium, their order, reversibility, and, most importantly, the significance in the occurrence of carcinomas. Particular attention, of course, is paid to $\mathrm{D}$ as a precancer process. Overall, there are no studies about the mechanisms of the association discussed in this paper. We can only suggest a possible mechanism underlying the association of variants of morphological changes in the bronchi adjacent to the tumor with the risk of distant metastasis in lung cancer. It is assumed that the mechanism of this relationship is due to the genetic determination of immune-inflammatory reactions in the development of chronic bronchitis and the types of epithelialstromal interactions associated with them. Shortly, various combinations of morphological changes in the bronchi reflect the constitutive features of parenchymal-stromal relations, which are formed under conditions of chronic inflammation in the bronchial wall.

A possible chain of events could be presented as follows: 1) constitutively isolated variants of the development of the

TABLE 5 | Univariate and multivariate Cox regression analyses of prognostic factors for 2-year metastasis-free survival in NSCLC patients.

\begin{tabular}{|c|c|c|c|c|c|}
\hline \multirow[t]{3}{*}{ Features } & \multirow[t]{3}{*}{ Level } & \multicolumn{4}{|c|}{ Metastasis-free survival } \\
\hline & & \multicolumn{2}{|c|}{ Univariate } & \multicolumn{2}{|c|}{ Multivariate } \\
\hline & & Hazard ratio $(95 \% \mathrm{Cl})$ & p-Value & Hazard ratio $(95 \% \mathrm{Cl})$ & p-Value \\
\hline \multirow[t]{2}{*}{ Risk group } & Low & \multicolumn{2}{|l|}{ Ref } & \multicolumn{2}{|l|}{ Ref } \\
\hline & High & \multirow{2}{*}{\multicolumn{2}{|c|}{ Ref }} & $0.88(0.54-1.29)$ & 0.5845 \\
\hline \multirow{2}{*}{ Type of bronchial lesions } & $B C H-S M-D-$ & & & \multicolumn{2}{|l|}{ Ref } \\
\hline & $\mathrm{BCH}-\mathrm{SM}+\mathrm{D}_{+}$ & $0.85(0.38-1.89)$ & 0.6993 & $0.85(0.36-2.01)$ & 0.7606 \\
\hline \multirow[t]{2}{*}{ Histologic type } & Squamous cell carcinoma & \multicolumn{2}{|l|}{ Ref } & \multicolumn{2}{|l|}{ Ref } \\
\hline & Adenocarcinoma & $1.04(0.71-1.52)$ & 0.8051 & $0.99(0.65-1.50)$ & 0.9855 \\
\hline \multirow{2}{*}{ Recurrence } & No & \multicolumn{2}{|l|}{ Ref } & \multicolumn{2}{|l|}{ Ref } \\
\hline & Yes & $0.63(0.39-1.01)$ & 0.0529 & $0.97(0.52-1.80)$ & 0.9312 \\
\hline Type of therapy & NAC-IORT- & \multicolumn{2}{|l|}{ Ref } & \multicolumn{2}{|l|}{ Ref } \\
\hline Tumor size & T3-4 & $1.07(0.73-1.57)$ & 0.7145 & $0.99(0.67-1.47)$ & 0.9956 \\
\hline \multirow[t]{2}{*}{ Nodal status } & Negative & \multicolumn{2}{|l|}{ Ref } & \multicolumn{2}{|l|}{ Ref } \\
\hline & Positive & $0.90(0.63-1.30)$ & 0.5956 & $1.01(0.66-1.55)$ & 0.9328 \\
\hline \multirow[t]{2}{*}{$A C$} & No & \multicolumn{2}{|l|}{ Ref } & \multicolumn{2}{|l|}{ Ref } \\
\hline & Yes & $0.91(0.64-1.31)$ & 0.6479 & $1.05(0.71-1.55)$ & 0.7795 \\
\hline Smoking status & Smoking & Ref & & Ref & \\
\hline & Non-smoking & $1.03(0.69-1.53)$ & 0.8750 & $0.99(0.66-1.46)$ & 0.9629 \\
\hline Grade & $1-2$ & Ref & & Ref & \\
\hline & 3 & $1.14(0.78-1.64)$ & 0.4839 & $0.88(0.60-1.29)$ & 0.5350 \\
\hline
\end{tabular}

NSCLC, non-small cell lung cancer; BCH, basal cell hyperplasia; SM, squamous cell metaplasia; D, dysplasia; NAC, neoadjuvant chemotherapy; IORT, intraoperative radiotherapy; AC, adjuvant chemotherapy. 
TABLE 6 | Univariate and multivariate Cox regression analyses of prognostic factors for 5-year metastasis-free survival in NSCLC patients.

\begin{tabular}{|c|c|c|c|c|c|}
\hline \multirow[t]{3}{*}{ Features } & \multirow[t]{3}{*}{ Level } & \multicolumn{4}{|c|}{ Metastasis-free survival } \\
\hline & & \multicolumn{2}{|c|}{ Univariate } & \multicolumn{2}{|c|}{ Multivariate } \\
\hline & & Hazard ratio $(95 \% \mathrm{Cl})$ & p-Value & Hazard ratio $(95 \% \mathrm{Cl})$ & p-Value \\
\hline \multirow[t]{2}{*}{ Risk group } & Low & Ref & & Ref & \\
\hline & High & $0.78(0.50-1.21)$ & 0.2745 & $0.67(0.46-1.14)$ & 0.1543 \\
\hline \multirow[t]{4}{*}{ Type of bronchial lesions } & $B C H-S M-D-$ & Ref & & Ref & \\
\hline & $B C H+S M-D-$ & 1.56 (1.09-2.72) & 0.0442 & $2.20(1.05-4.58)$ & 0.0209 \\
\hline & $B C H+S M+D-$ & $1.18(0.58-2.38)$ & 0.7125 & $1.50(0.69-3.25)$ & 0.6981 \\
\hline & $B C H-S M+D+$ & $1.11(0.50-2.48)$ & 0.8219 & $1.03(0.43-2.47)$ & 0.4496 \\
\hline \multirow[t]{2}{*}{ Histologic type } & Squamous cell carcinoma & Ref & & Ref & \\
\hline & Adenocarcinoma & $0.85(0.53-1.38)$ & 0.5343 & $0.92(0.56-1.49)$ & 0.7372 \\
\hline \multirow[t]{2}{*}{ Recurrence } & No & Ref & & Ref & \\
\hline & Yes & $0.72(0.42-1.26)$ & 0.2606 & $1.06(0.55-2.03)$ & 0.8506 \\
\hline \multirow[t]{3}{*}{ Type of therapy } & NAC-IORT- & Ref & & Ref & \\
\hline & $N A C+I O R T-$ & $0.78(0.51-1.19)$ & 0.8574 & $0.52(0.28-1.01)$ & 0.0704 \\
\hline & $N A C+I O R T+$ & $0.65(0.41-1.03)$ & 0.1710 & $0.72(0.45-1.51)$ & 0.9939 \\
\hline \multirow[t]{2}{*}{ Gender } & Male & Ref & & Ref & \\
\hline & Female & $1.50(0.81-2.79)$ & 0.1948 & $1.40(0.75-2.61)$ & 0.2871 \\
\hline \multirow[t]{2}{*}{ Tumor size } & T1-2 & Ref & & Ref & \\
\hline & T3-4 & $0.89(0.57-1.38)$ & 0.6138 & $0.98(0.62-1.56)$ & 0.9638 \\
\hline \multirow[t]{2}{*}{ Nodal status } & Negative & Ref & & Ref & \\
\hline & Positive & $1.02(0.64-1.62)$ & 0.9134 & $0.86(0.52-1.43)$ & 0.5821 \\
\hline \multirow[t]{2}{*}{$\mathrm{AC}$} & No & Ref & & Ref & \\
\hline & Yes & $0.94(0.61-1.45)$ & 0.7930 & $0.98(0.63-1.55)$ & 0.9638 \\
\hline \multirow[t]{2}{*}{ Smoking status } & Smoking & Ref & & Ref & \\
\hline & Non-smoking & $0.97(0.62-1.51)$ & 0.9052 & $1.02(0.66-1.58)$ & 0.9183 \\
\hline \multirow[t]{2}{*}{ Grade } & $1-2$ & Ref & & Ref & \\
\hline & 3 & $1.24(0.79-1.94)$ & 0.3300 & $0.95(0.59-1.51)$ & 0.8390 \\
\hline
\end{tabular}

NSCLC, non-small cell lung cancer; BCH, basal cell hyperplasia; SM, squamous cell metaplasia; D, dysplasia; NAC, neoadjuvant chemotherapy; IORT, intraoperative radiotherapy; AC, adjuvant chemotherapy.

immune-inflammatory reaction in the bronchial mucosa determine the dominant spectrum of cytokines affecting the epithelium. 2) Depending on the cytokines affecting the epithelium of the bronchi and/or the response of the epithelium to the action of cytokines, different morphological changes and their combinations develop in the bronchi. 3) Different variants of morphological changes in small bronchi in NSCLC are markers of discrete variants of epithelial-stromal relations during chronic inflammation and can be a criterion for discriminating patients by group. 4) The invasive phenotype of primary tumor cells and their ability to intravasate are largely formed under the influence of the microenvironment. 5) In the tumor microenvironment, immunoinflammatory reactions almost are observed ("non-healing wound"). 6) The nature of inflammation and the spectrum of cytokines in the tumor microenvironment are determined not only by the tumor specificity but also by the reflection of the constitutive features of the development of immune-inflammatory reactions. 7) Constitutive features of immune-inflammatory reactions and epithelial-stromal relations in the wall of bronchi adjacent to the tumor reflect significant manifestations of

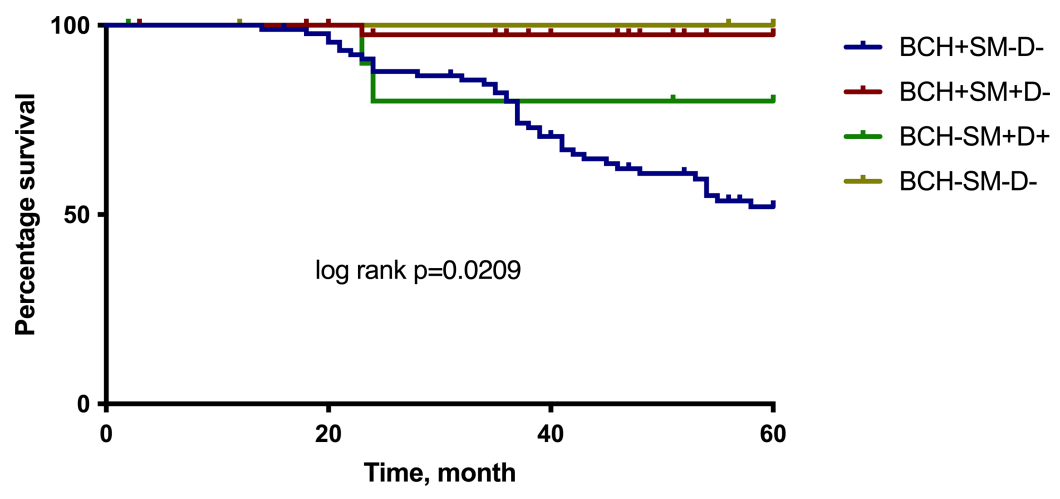

FIGURE 4 | The 5-year MFS for NSCLC patients according to the different types of bronchial lesions. Log rank test. MFS, metastasis-free survival. 


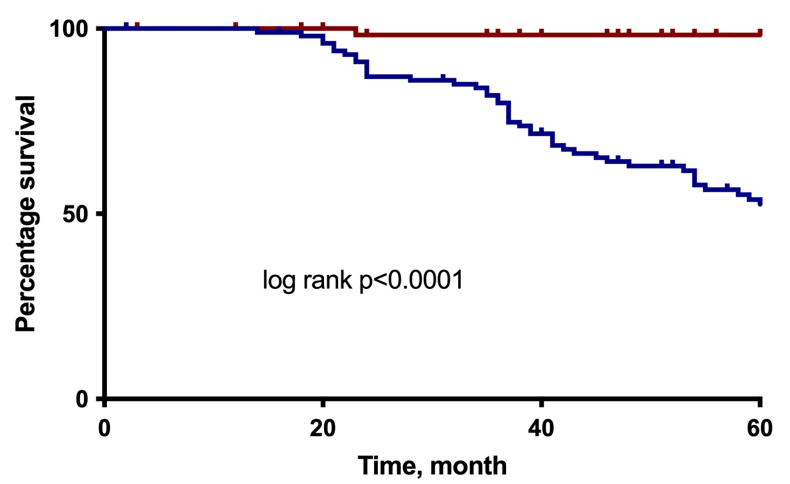

FIGURE 5 | The 5-year MFS for NSCLC patients according to the group of low and high risk of distant metastasis. Log rank test. MFS, metastasis-free survival.

immune-inflammatory reactions in the tumor microenvironment, including their ability to increase the invasive and intravasation potential and the ability to metastasize. 8) The morphological type of precancerous changes in the bronchial epithelium of the bronchi adjacent to the tumor is a prognostic sign of the risk of metastasis.

\section{DATA AVAILABILITY STATEMENT}

The raw data supporting the conclusions of this article will be made available by the authors, without undue reservation.

\section{ETHICS STATEMENT}

The studies involving human participants were reviewed and approved by local ethics committee of the Cancer Research Institute, Tomsk NRMC, on December 10, 2012 (the number

\section{REFERENCES}

1. Ferlay J, Colombet M, Soerjomataram I, Parkin DM, Piñeros M, Znaor A, et al. Cancer statistics for the year 2020: An overview. Int J Cancer (2021) 149:778-89. doi: 10.1002/ijc.33588

2. Gold KA, Kim ES, Liu DD, Yuan P, Behrens C, Solis LM, et al. Prediction of Survival in Resected Non-Small Cell Lung Cancer Using a Protein Expression-Based Risk Model: Implications for Personalized Chemoprevention and Therapy. Clin Cancer Res (2014) 20:1946-54. doi: 10.1158/1078-0432.CCR-13-1959

3. Demicheli R, Fornili M, Ambrogi F, Higgins K, Boyd JA, Biganzoli E, et al. Recurrence Dynamics for Non-Small-Cell Lung Cancer: Effect of Surgery on the Development of Metastases. J Thorac Oncol (2012) 7:723-30. doi: 10.1097/ JTO.0b013e31824a9022

4. Fan C, Gao S, Hui Z, Liang J, Lv J, Wang X, et al. Risk Factors for Locoregional Recurrence in Patients With Resected N1 Non-Small Cell Lung Cancer: A Retrospective Study to Identify Patterns of Failure and Implications for Adjuvant Radiotherapy. Radiat Oncol (2013) 8:286. doi: 10.1186/1748717X-8-286

5. Postmus PE, Kerr KM, Oudkerk M, Senan S, Waller DA, Vansteenkiste J, et al. Early and Locally Advanced Non-Small-Cell Lung Cancer of approval is 16). The patients/participants provided their written informed consent to participate in this study.

\section{AUTHOR CONTRIBUTIONS}

Conceptualization: OP and VP. Methodology: OP and MZ. Investigation: OP, LT, TG, and DP. Provided patients' data: ER, ST, and SM. Writing-original draft preparation: OP. Writing-review and editing: LT, VP, and SV. Project administration: OP. Funding acquisition: ED. All authors contributed to the article and approved the submitted version.

\section{FUNDING}

This work was supported by the Russian Science Foundation [grant number 20-75-10060].

(NSCLC): ESMO Clinical Practice Guidelines for Diagnosis, Treatment and Follow-Up. Ann Oncol (2017) 28:iv1-iv21. doi: 10.1093/annonc/ $\mathrm{mdx} 222$

6. Pankova OV, Denisov EV, Ponomaryova AA, Gerashchenko TS, Tuzikov SA, Perelmuter VM. Recurrence of Squamous Cell Lung Carcinoma Is Associated With the Co-Presence of Reactive Lesions in Tumor-Adjacent Bronchial Epithelium. Tumor Biol (2016) 37:3599-607. doi: 10.1007/s13277-015-4196-2

7. Denisov EV, Schegoleva AA, Gerashchenko TS, Skryabin NA, Sleptcov AA, Yakushina VD, et al. Gene Expression Profiling Revealed 2 Types of Bronchial Basal Cell Hyperplasia and Squamous Metaplasia With Different Progression Potentials. Appl Immunohistochem Mol Morphol (2020) 28:477-83. doi: 10.1097/PAI.0000000000000762

8. Brierley JD, Gospodarowicz MK, Wittekind C. TNM Classification of Malignant Tumours. 8th Edition. New York, USA: Wiley-Blackwell (2017).

9. Greenberg AK, Yee H, Rom WN. Preneoplastic Lesions of the Lung. Respir Res (2002) 3:13. doi: 10.1186/rr170

10. Kerr KM, Popper HH. The Differential Diagnosis of Pulmonary Pre-Invasive Lesions. Eur Respir Monogr (2007) 39:37. doi: 10.1183/1025448x.00039003

11. Pankova OV, Rodionov EO, Miller SV, Tuzikov SA, Tashireva LA, Gerashchenko TS, et al. Neoadjuvant Chemotherapy Combined With Intraoperative Radiotherapy Is Effective to Prevent Recurrence in High-Risk 
Non-Small Cell Lung Cancer (NSCLC) Patients. Transl Lung Cancer Res (2020) 9:988-99. doi: 10.21037/tlcr-19-719

Conflict of Interest: The authors declare that the research was conducted in the absence of any commercial or financial relationships that could be construed as a potential conflict of interest.

Publisher's Note: All claims expressed in this article are solely those of the authors and do not necessarily represent those of their affiliated organizations, or those of the publisher, the editors and the reviewers. Any product that may be evaluated in this article, or claim that may be made by its manufacturer, is not guaranteed or endorsed by the publisher.

Copyright (c) 2021 Pankova, Tashireva, Rodionov, Miller, Tuzikov, Pismenny, Gerashchenko, Zavyalova, Vtorushin, Denisov and Perelmuter. This is an openaccess article distributed under the terms of the Creative Commons Attribution License (CC BY). The use, distribution or reproduction in other forums is permitted, provided the original author(s) and the copyright owner(s) are credited and that the original publication in this journal is cited, in accordance with accepted academic practice. No use, distribution or reproduction is permitted which does not comply with these terms. 